\title{
A Case of Cutaneous Inflammatory Myofibroblastic Tumor
}

\author{
Soo Bin Son, M.D., Young Soo Heo, M.D., Won Woong Shin, M.D., Tae Seok Oh, M.D., \\ Hae Jun Song, M.D., Chil Hwan Oh, M.D. \\ Department of Dermatology, College of Medicine, Korea University, Seoul, Korea
}

Pseudo-inflammatory tumors are also known as plasma cell granuloma, inflammatory pseudo-tumor and inflammatory myofibroblastic tumor, and these tumors are a group of highly variable proliferations of myofibroblastic cells that are associated with a prominent inflammatory infiltrate. This tumor is known to most commonly occur in the lungs, bladder and gastrointestinal system with only a few cases having been reported in the skin. A previously healthy 26-year-old man presented with a 6-year history of an intermittently pruritic lesion on his back. On the histologic examination, there were spindle cells in fascicles and a mixed inflammatory cellular infiltrate of plasma cells and lymphocytes. A diagnosis of inflammatory fibroblastic tumor was made and the nodule was surgically removed. We report here on an additional case of this rare cutaneous entity, and it is probably the first such report from Korea. (Ann Dermatol 22(1) $91 \sim 95,2010$ )

-Keywords-

Myofibroblastic, Pseudo-inflammatory

\section{INTRODUCTION}

Inflammatory myofibroblastic tumor is also known as IMT, inflammatory pseudotumor, plasma cell granuloma and pseudo-inflammatory tumor, and it is a generic term that is applied to a variety of neoplastic and non-neoplastic entities that share a common histologic appearance, namely, a

Received September 30, 2008, Revised July 22, 2009, Accepted for publication July 22, 2009

Reprint request to: Chil Hwan Oh, M.D., Department of Dermatology, College of Medicine, Korea University Guro Hospital, 97, Gurodong-gil, Guro-gu, Seoul 152-703, Korea. Tel: 82-2-2626-1300, Fax: 82-2-838-2359, E-mail: choh@korea.ac.kr cytologically bland spindle cell proliferation with a prominent, usually chronic inflammatory infiltrate. IMT occurs in various organs and among them, the lung is the most frequently affected organ followed by the liver, lymph node and spleen. Yet only 16 cases of cutaneous IMT have been reported in the literature. We report here on an additional case of this rare cutaneous entity.

\section{CASE REPORT}

A previously healthy 26-year-old man presented with a 6-year history of an intermittently pruritic lesion on his back. There was no history of preceding trauma, surgery or arthropod bites. There were no lymphadenopathies or constitutional symptoms, and the laboratory findings were unremarkable. On examination, there was a brownish colored, palpable indurated nodule (Fig. 1). The overlying skin showed slight red-brown discoloration with a rough surface. We elected to perform excisional biopsy for making the diagnosis and the pathology report stated that the tumor was composed of a proliferation of spindle cells. These spindle cells were typically uniform and predominantly myofibroblastic in appearance, with palely eosinophilic cytoplasm and ovoid vesicular nuclei. A heavy infiltration of plasma cells was observed predominantly in the periphery and to a lesser extent in the central area of the tumor (Fig. 2). Occasional lymphoid follicles were observed around the tumor. The spindle cells were immunoreactive for smooth muscle actin and desmin, but they were negative for S-100 protein and C-kit (Fig. 3). The inflammatory component was polyclonal with both kappaand lambda-positive populations.

After considering all these findings, the lesion was diagnosed as an inflammatory myofibroblastic tumor. The lesion was surgically removed and the patient has remained healthy 11 months after surgery. 

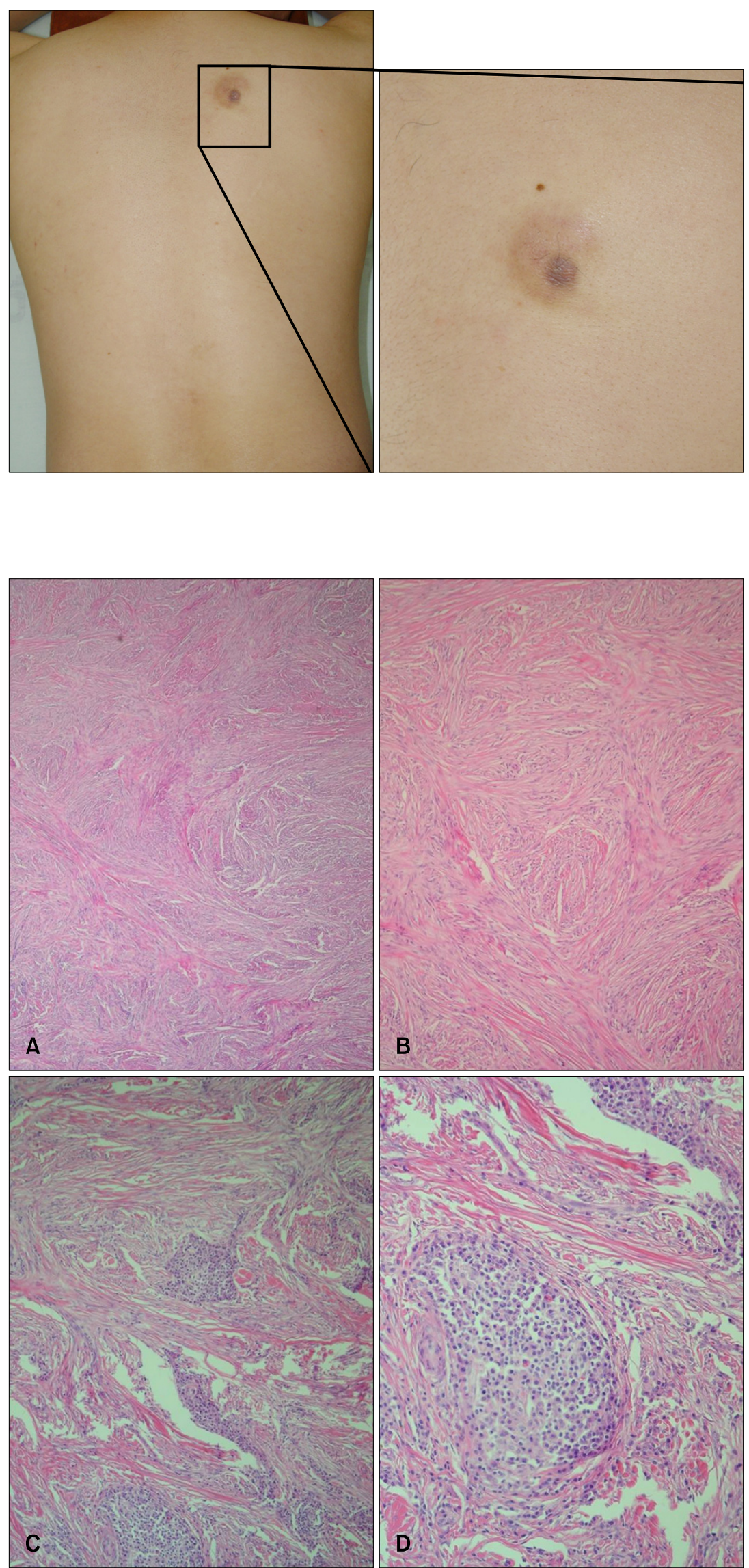

B
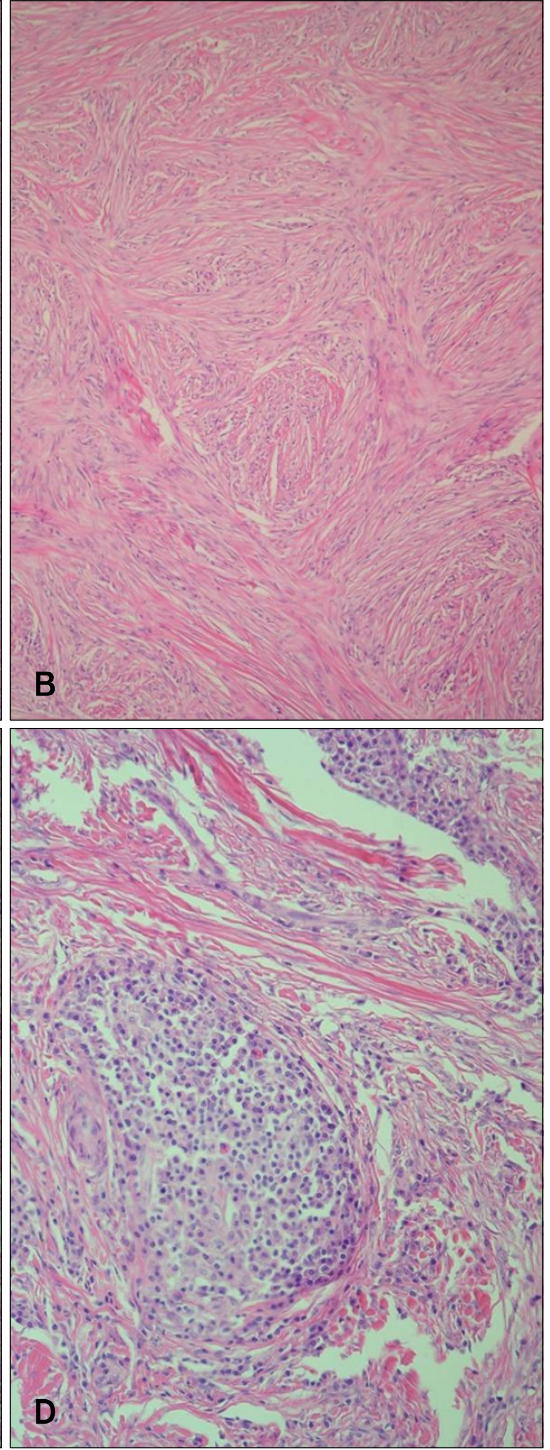

Fig. 1. A brownish colored palpable indurated nodule with a rough surface on the upper back.
Fig. 2. The tumor cells had plump spindleshaped cytoplasm and the cells were arranged in fascicles or epithelioid nests with collagenous stroma (A: H\&E, $\times 40, \quad B: H \& E, \times 100)$. The inflammatory part showed a cellular infiltration that consisted of plasma cells and lymphocytes (C: H\&E, $\times 100, D: H \& E, \times 200)$. 

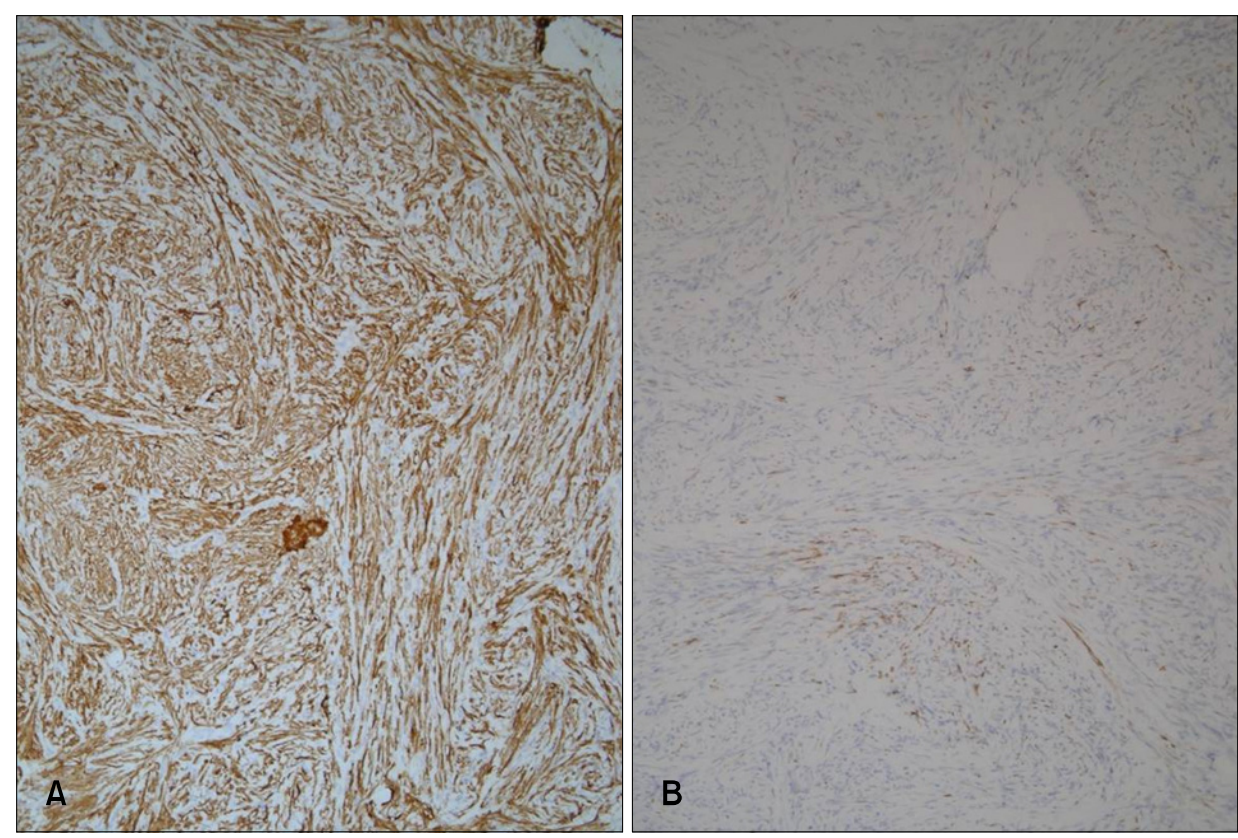

Fig. 3. (A) Staining for smooth muscle actin (SMA) highlights the spindle cells and confirms their myofibroblastic nature (Immunohistochemistry for SMA, $\times 100$ ). (B) The tumor cells show a weak positive immunoreaction for desmin (Immunohistochemistry for desmin, $\times 100)$.

Table 1. Summary of the clinical features of cutaneous IMTs in the literature

\begin{tabular}{|c|c|c|c|c|c|c|}
\hline Author & No. & Gender & Age (yrs) & Location & Treatment & Country \\
\hline \multirow[t]{4}{*}{ Hurt et al. ${ }^{10}$ (1990) } & 1 & M & - & Arm & Excision & \multirow[t]{4}{*}{ USA } \\
\hline & 2 & M & - & Arm & Excision & \\
\hline & 3 & $\mathrm{~F}$ & - & Calf & Excision & \\
\hline & 4 & $\mathrm{~F}$ & - & Neck & Excision & \\
\hline Yang $^{11}$ (1993) & 5 & M & 44 & Hand & Excision & USA \\
\hline Vadmal and Pellegrini $^{12}$ (1999) & 6 & $\mathrm{~F}$ & 49 & Arm & Excision & USA \\
\hline \multirow[t]{3}{*}{ Nakajima et al. ${ }^{13}(2001)$} & 7 & $\mathrm{~F}$ & 25 & Thigh & Excision & \multirow[t]{3}{*}{ Japan } \\
\hline & 8 & M & 89 & Shoulder & Excision & \\
\hline & 9 & $\mathrm{~F}$ & 70 & Scalp & Excision & \\
\hline \multirow[t]{3}{*}{ El Shabrawi-Caelen et al. ${ }^{14}$ (2004) } & 10 & M & 15 & Shoulder & Excision & \multirow[t]{3}{*}{ Austria } \\
\hline & 11 & $\mathrm{~F}$ & 56 & Arm & Excision & \\
\hline & 12 & $\mathrm{~F}$ & 56 & Arm & Excision & \\
\hline Yung et al. ${ }^{15}$ (2005) & 13 & M & 33 & Shoulder & Excision & England \\
\hline Saricaoglu et al. ${ }^{16}$ (2006) & 14 & M & 57 & Cheek & Excision & Turkey \\
\hline Pagni $^{17}(2007)$ & 15 & M & 63 & Arm & - & Italia \\
\hline Gonzalez-Vela et al. ${ }^{18}$ (2007) & 16 & M & 10 & Arm & Excision & Spain \\
\hline
\end{tabular}

\section{DISCUSSION}

IMT was first described in the lung in the 1950s, and at that time it was considered a reparative post inflammatory condition rather than a neoplastic process ${ }^{1}$. In the early 1990s, Meis and Enzinger ${ }^{2}$ published an article about these ambiguous tumors that occurred in children and adolescents, which they termed "inflammatory pseudosarcoma". In 1995, Coffin et al. ${ }^{3}$ reported on 84 cases of extrapulmonary IMT that overlapped clinically and histologically with inflammatory fibrosarcoma. Over the last two decades, IMT has emerged as a distinct entity with characteristic clinical, pathologic and molecular features. Because the terms "inflammatory pseudotumor" and "inflammatory myofibroblastic tumor" are interchangeably used in the literature, accurate data regarding the incidence and anatomic distribution of IMT is difficult to obtain. However, several articles reported that the most common anatomic locations are the lung, abdominopelvic region and retroperitoneum, but virtually any site may be involved, including the somatic soft tissues, bone, larynx, uterus and central nervous system ${ }^{4-8}$. One recent review of 44 IMTs reported that approximately one third of the cases were pulmonary IMTs and two thirds were extra-pulmo- 
nary IMTs, and only one case manifested in the skin ${ }^{9}$. Cutaneous IMT is very rare and to the best of our knowledge, only 16 cases of cutaneous IMT have been reported. The patient characteristics and anatomic locations of the reported lesions are listed in Table $1^{10-18}$.

The clinical presentation of cutaneous IMT is not specific and this tumor varies in size and shape. The patients generally present with a mass without specific symptoms, so this entity seldom enters the differential diagnosis at the time of the initial evaluation. But IMT is histologically characterized by a spindle cell proliferation and a prominent inflammatory infiltrate. The spindle cells of IMT are predominantly myofibroblastic in appearance and therefore, IMTs are positive for smooth muscle actin in $80 \sim$ $90 \%$ of the cases and they express desmin and calponin in $60 \sim 70 \%{ }^{14,19}$. Mild nuclear pleomorphism may be seen, but hyperchromasia is absent and atypical mitoses are also rare. The inflammatory portion is primarily composed of plasma cells and lymphocytes, with occasional admixed eosinophils and neutrophils. The plasma cell infiltrate is polyclonal.

Histologically, IMT of the skin should be differentiated from dermatofibrosarcoma protuberans (DFSP), sclerosing lymphoma, solitary fibrous tumor, nodular fasciitis and other infectious process ${ }^{12}$. DFSP typically shows spindle cells infiltrating to the adjacent area and any inflammatory infiltrate is minimal or absent. Most DFSP are CD-34 positive. Sclerosing lymphoma rarely occurs in the skin and this lesion is composed of large atypical lymphocytes. Nodular fasciitis usually presents as a rapidly growing nodule and it shows a proliferation of plump, young myofibroblast in a myxoid stroma.

The main stay of therapy usually includes surgical excision, and recurrences have been reported in up to $25 \sim$ $40 \%$ of the cases of pulmonary and extrapulmonary IMTs. Recurrence has been suggested to be more common if the lesions are extrapulmonary ${ }^{20}$.

In conclusion, we report here on a rare case of cutaneous IMT with a review of the medical literature, and this is the first case of cutaneous IMT reported from Korea. Including the present case, none of the previously reported 17 cases of cutaneous IMT have shown constitutional symptoms, local recurrence, lymph node involvement or malignant behavior. There is still controversy regarding the pathogenesis, that is, whether it is a reactive process due to some stimulus or it is a true neoplasm ${ }^{18}$. Although the precise etiopathogenesis and biologic behavior of IMT are unknown, these tumors should be approached with caution, and particularly when they show a myofibroblastic proliferation stimulating a low grade mesenchymal neoplasm.

\section{REFERENCES}

1. Umiker WO, Iverson L. Postinflammatory tumors of the lung; report of four cases simulating xanthoma, fibroma, or plasma cell tumor. J Thorac Surg 1954;28:55-63.

2. Meis JM, Enzinger FM. Inflammatory fibrosarcoma of the mesentery and retroperitoneum. A tumor closely simulating inflammatory pseudotumor. Am J Surg Pathol 1991;15:11461156.

3. Coffin CM, Watterson J, Priest JR, Dehner LP. Extrapulmonary inflammatory myofibroblastic tumor (inflammatory pseudotumor). A clinicopathologic and immunohistochemical study of 84 cases. Am J Surg Pathol 1995;19:859-872.

4. Wenig BM, Devaney K, Bisceglia M. Inflammatory myofibroblastic tumor of the larynx. A clinicopathologic study of eight cases simulating a malignant spindle cell neoplasm. Cancer 1995;76:2217-2229.

5. Sciot R, Dal Cin P, Fletcher CD, Hernandez JM, Garcia JL, Samson I, et al. Inflammatory myofibroblastic tumor of bone: report of two cases with evidence of clonal chromosomal changes. Am J Surg Pathol 1997;21:1166-1172.

6. Ramachandra S, Hollowood K, Bisceglia M, Fletcher CD. Inflammatory pseudotumour of soft tissues: a clinicopathological and immunohistochemical analysis of 18 cases. Histopathology 1995;27:313-323.

7. Hausler M, Schaade L, Ramaekers VT, Doenges M, Heimann G, Sellhaus B. Inflammatory pseudotumors of the central nervous system: report of 3 cases and a literature review. Hum Pathol 2003;34:253-262.

8. Rabban JT, Zaloudek CJ, Shekitka KM, Tavassoli FA. Inflammatory myofibroblastic tumor of the uterus: a clinicopathologic study of 6 cases emphasizing distinction from aggressive mesenchymal tumors. Am J Surg Pathol 2005;29: 1348-1355.

9. Kovach SJ, Fischer AC, Katzman PJ, Salloum RM, Ettinghausen SE, Madeb R, et al. Inflammatory myofibroblastic tumors. J Surg Oncol 2006;94:385-391.

10. Hurt MA, Santa Cruz DJ. Cutaneous inflammatory pseudotumor. Lesions resembling "inflammatory pseudotumors" or "plasma cell granulomas" of extracutaneous sites. Am J Surg Pathol 1990;14:764-773.

11. Yang M. Cutaneous inflammatory pseudotumor: a case report with immunohistochemical and ultrastructural studies. Pathology 1993;25:405-409.

12. Vadmal MS, Pellegrini AE. Inflammatory myofibroblastic tumor of the skin. Am J Dermatopathol 1999;21:449-453.

13. Nakajima T, Sano S, Itami S, Yoshikawa K. Cutaneous inflammatory pseudotumour (plasma cell granuloma). $\mathrm{Br} \mathrm{J}$ Dermatol 2001;144:1271-1273.

14. El Shabrawi-Caelen L, Kerl K, Cerroni L, Soyer HP, Kerl H. Cutaneous inflammatory pseudotumor--a spectrum of various diseases? J Cutan Pathol 2004;31:605-611.

15. Yung A, Merchant W, Goulden V. A case of isolated cutaneous pseudo-inflammatory tumour. Clin Exp Dermatol 2005;30:369-372.

16. Saricaoglu H, Akin S, Adim SB, Karadogan SK. Cutaneous inflammatory pseudotumour. J Eur Acad Dermatol Venereol 
2006;20:750-751.

17. Pagni F. Cutaneous inflammatory pseudotumor (plasmocytoid granuloma). Pathologica 2007;99:84-86.

18. Gonzalez-Vela MC, Val-Bernal JF, Arce FP, Gomez-Roman J, Gonzalez-Lopez MA, Fernandez-Llaca JH. Presence of human herpesvirus-8 in inflammatory myofibroblastic tumor of the skin. J Eur Acad Dermatol Venereol 2007;21:399-401.
19. Gleason BC, Hornick JL. Inflammatory myofibroblastic tumours: where are we now? J Clin Pathol 2008;61:428-437.

20. Coffin CM, Dehner LP, Meis-Kindblom JM. Inflammatory myofibroblastic tumor, inflammatory fibrosarcoma, and related lesions: an historical review with differential diagnostic considerations. Semin Diagn Pathol 1998;15:102-110. 